\title{
Study of harmonic microstructure development during Spark Plasma Sintering (SPS) of $\beta$-CEZ titanium alloy
}

\author{
Benoît Denand $^{1}$, Bhupendra Sharma ${ }^{1,3}$, Guillaume Geandier ${ }^{1}$, Guy Dirras ${ }^{2}$, Kei Ameyama ${ }^{3}$, Yudong Zhang ${ }^{4}$, Elisabeth Aeby- \\ Gautier $^{1}$
}

${ }^{1}$ Universite de Lorraine, Institut Jean Lamour (IJL), UMR 7198 - CNRS, Nancy, France

${ }^{2}$ Université Paris 13, Laboratoire des Sciences des Procédés et des Matériaux (LSPM), Villetaneuse, France,

${ }^{3}$ Department of Mechanical Engineering, College of Science and Engineering, Ritsumeikan University, Noji-Higashi, KusatsuCity, Shiga, Japan

${ }^{4}$ Universite de Lorraine, Laboratoire d'Etude des Microstructures et de Mécanique des Matériaux (LEM3), UMR 7239, Metz, France

\begin{abstract}
The present study focuses on the formation of harmonic microstructures in a metastable $\beta$ titanium alloy, the $\beta$-Cez alloy ( $\mathrm{T}_{\beta}=$ $890^{\circ} \mathrm{C}$ ). Previous studies showed that harmonic structures obtained by a powder metallurgy route led to an increase in mechanical properties. In this study, the harmonic structure was obtained after a Mechanical Milling of the Initial Powder followed by Spark Plasma Sintering.

The phase transformations occurring in the Initial Powder and Mechanical Milled powders during a heat treatment similar to the SPS one were studied. Electrical resistivity, high energy XRD and SEM-EBSD were used to characterize the evolution of phases and microstructures and highlight the effect of the thermal treatment and the milling. It was shown that after thermal treatment of Mechanical Milled powders, a harmonic $\alpha+\beta$ microstructure is obtained consisting of nodular $\alpha$ grains in the powder shell and $\alpha$ lamellae in the powder core. The stress/strain induced martensite formed during the milling associated with the heavier deformation at the powder surface areas contributes highly to the formation of network arrangement of nodular $\alpha$ grains by a recovery/recrystallization phenomenon of $\beta$ and $\alpha$ phases during the heating.
\end{abstract}

\section{Introduction}

Metastable $\beta$-Ti alloys are a class of titanium alloys having great potential to be used in versatile applications, such as aerospace, automotive and biomedical applications, owing to their outstanding chemical and mechanical properties [1][2]. In such typical engineering applications, an appropriate balance of strength and ductility is required, simultaneously. Recent studies have shown that a blend of fine and coarse grain size distribution in the microstructure matrix is very useful in achieving an attractive combination of high strength and acceptable ductility [3][4]. In particular, Ameyama and co-workers proposed an elegant microstructure design, called "harmonic structure", which essentially is a bimodal microstructure wherein the large-grained areas ("core") are present as embedded islands in the matrix of the three-dimensional continuously connected network ("shell") of finegrained areas [5]. The concept of harmonic structure design has been successfully applied in a variety of materials [5][6][7]. All the harmonic microstructure designed materials demonstrated a significantly better performance [8][9] as compared to their homogeneous fine or coarse-grained counterparts. However, until now, most of the studies were focused on the various fabrication processes and their corresponding mechanical properties, and no detailed studies of phase and microstructure evolutions, during fabrication of harmonic structure materials, have been reported.

Hence, it appears clear that investigating the mechanisms occurring during phase transformations are key steps to design and control the microstructures with some desired properties (function of size, fraction of shell and core grains). In order to control the harmonic arrangement formation, it is necessary to understand the microstructure development occurring during the milling 
and the sintering process. Various techniques: in situ High Energy XRD (HEXRD), electrical resistivity, scanning electron microscopy (EDX, EBSD)) have been used to characterize the phases and microstructures after the Spark Plasma Sintering (SPS) treatment, or during thermal treatment of Initial Powder (IP) and Mechanical Milled (MM) powders in order to analyse the effect of the thermal treatment and the milling.

\section{Material and experiments}

Table-1: Composition of $\beta-C E Z$ Ti alloy used.

\begin{tabular}{|c|c|c|c|c|c|c|c|c|c|c|}
\hline Elements & $\mathrm{Al}$ & $\mathrm{Mo}$ & $\mathrm{Cr}$ & $\mathrm{Zr}$ & $\mathrm{Sn}$ & $\mathrm{Fe}$ & $\mathrm{O}$ & $\mathrm{N}$ & $\mathrm{C}$ & $\mathrm{Ti}$ \\
\hline Mass\% & 5 & 4 & 2 & 4 & 2 & 1 & $\begin{array}{c}1055 \\
(\mathrm{ppm})\end{array}$ & $\begin{array}{c}59 \\
(\mathrm{ppm})\end{array}$ & $\begin{array}{c}52 \\
(\mathrm{ppm})\end{array}$ & Bal. \\
\hline
\end{tabular}

The chemical composition of the starting material $\beta$-CEZ Ti alloy [10] is given in Table 1. Powders were prepared at Ritsumeikan University - Japan [11]. They were obtained from the rod by a plasma Rotating Electrode Process (PREP) and had an average particle size of $150 \mu \mathrm{m}$. The initial powder (IP) was mechanically milled (MM), during $25 \mathrm{~h}$, in a planetary ball mill using steel vials, filled with argon gas, and steel balls. Subsequently, both IP and MM powders were sintered by SPS using graphite die and punch, at $800{ }^{\circ} \mathrm{C}$ for 30 min under high vacuum and $50 \mathrm{MPa}$ applied pressure. The SPS thermal treatment comprises a heating at $0.8^{\circ} \mathrm{C} / \mathrm{s}$ up to $800^{\circ} \mathrm{C}$, followed by a dwell during $30 \mathrm{~min}$ and a cooling to room temperature at $0.23^{\circ} \mathrm{C} / \mathrm{s}$. The sintered specimens, prepared from IP and MM powders, will be referred to IP-SPS and MM-SPS specimens.

The phase transformation kinetics were carried out on one side by in-situ electrical resistivity measurement on dense specimens and, on the other side, by high-energy X-ray diffraction methods on powders and dense specimens. For HEXRD, powders were submitted to the same SPS thermal treatment. Powders were inserted in a quartz capillary tube, with an S-type thermocouple put inside the powders in order to accurately control the programmed temperature cycle. The HEXRD experiments were performed at the European Synchrotron Radiation Facility (ESRF) on ID15A beamline. The radiation used was HE X-Ray with a monochromatic beam of $90 \mathrm{keV}$. The capillary tube containing the powder was placed at the centre of an in-house made radiant furnace [12] on a sample holder with rotating platform. The capillary was inside a quartz chamber with an argon gas flow to limit powder oxidation. In order to obtain good counting statistics, one pattern was recorded every complete rotation of the quartz capillary. A "Pilatus $2 \mathrm{M}$ " detector placed at $0.7 \mathrm{~m}$ from the sample allowed the collection of the complete Debye-Scherrer rings until the angle of $9^{\circ}$ in the $2 \theta$ range. Data integration was processed using PyFAI software to convert the $2 \mathrm{D}$ images into classical 1D diffractograms usable for further analysis [13]. The diffraction diagrams were analysed using the multiphase Rietveld refinement with the software FullProf [14][15].

Electrical resistivity measurements were performed on dense SPS specimens using a rapid in-house dilatometer. Specimens were cylindrical, $3.8 \mathrm{~mm}$ diameter and $20 \mathrm{~mm}$ length. IP-SPS specimens were first heat-treated in the $\beta$ temperature range and quenched to obtain a $\beta$ metastable phase, with equiaxed grains. Then, the similar heat treatment as the one used during SPS process was carried out for the IP-SPS specimen.

In order to characterize the microstructure and grain morphologies evolutions, several treatments were performed with a controlled cooling at different stages of the treatment (heating, holding and cooling). Heat treatments were interrupted by helium gas quenching at $450^{\circ} \mathrm{C}, 800^{\circ} \mathrm{C}$, and $800^{\circ} \mathrm{C}$ holding during $30 \mathrm{~min}$. The microstructures at each stage were observed by a scanning electron microscope for morphology analyses and EBSD maps.

\section{Results}

After sintering, the IP-SPS and MM-SPS specimen exhibit a mixture of $\alpha+\beta$ with similar $\alpha$ phase fraction. Morphology of $\alpha$ phase is different. Only for the MM-specimen, the $\alpha$ arrangement exhibits a harmonic structure (figure $6 \mathrm{~d}$ ). In order to understand the harmonic structure formation in MM specimen, a study of phase transformations in the IP and the MM powders was realized during mechanical milling and the "SPS thermal treatment".

\subsection{Characterisations of IP and MM powders}

Characterisations of IP and MM powders reveal a large difference in the initial state before SPS treatment. Figure 1 shows the micrographs of Ti $\beta$-CEZ powder particles of initial (Fig. 1a) and mechanically milled (Fig. 1b) powder particles. The 
IP powders were spherical. Some particles may have satellites and reveal segregations. The MM powders are no more spherical, and present plastic deformation at the surface. At the surface and inner the MM powder, strain-induced acicular martensite plates are observed, as shown in Fig. 1b.

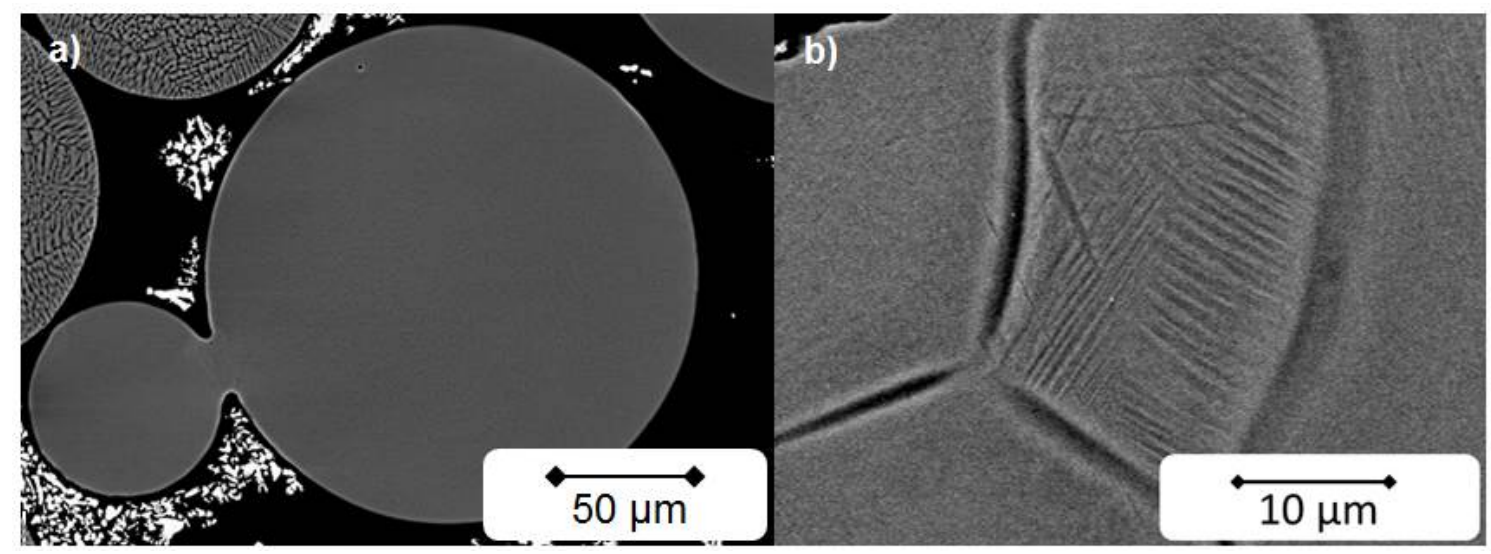

Figure 1: Initial microstructure for powders a) IP fully $\beta$ b) MM mix of $\beta+\alpha "$

XRD diffraction diagrams given Fig 2 confirm those differences. The initial powder presents a single $\beta$ phase (Fig. 3a) whereas the structure of the milled powder is a mixture of $\beta$ phase and a large amount (73 wt.\%) of strain induced martensitic $\alpha$ " phase. The beta metastable state of the IP powders is expected considering the rapid cooling during the powder processing [16]. The presence of $\omega_{\text {ath }}$ is suspected to be present. Formation of strain induced martensite was also reported for this alloy on massive specimen [17].
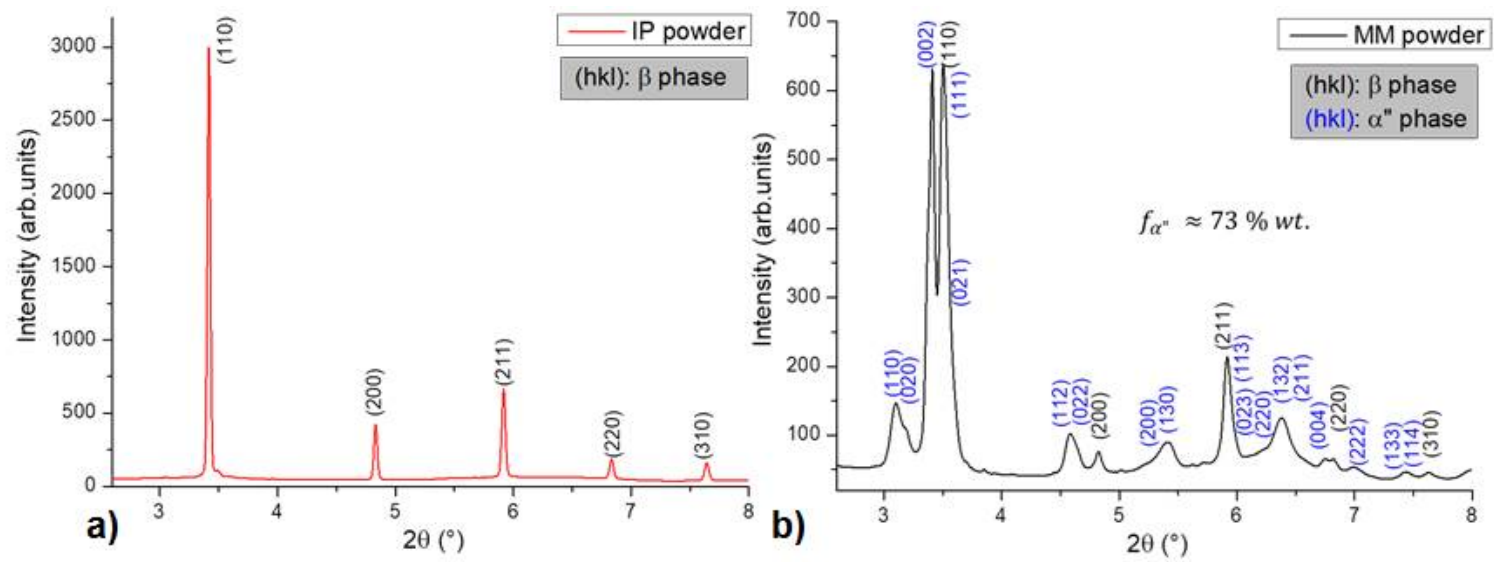

Figure 2: XRD diffractograms of a) initial powder and b) mechanically milled powder.

\subsection{Transformation kinetics in $\beta$-CEZ IP-SPS specimen}

In order to get the phase evolutions occurring in the IP powders that were in a $\beta$-metastable state, transformations were characterized on a dense IP-specimen that was first heat treated in the high temperature $\beta$ range and further quenched to RT. The "SPS heat treatment" was applied. Two in-situ methods were used: electrical resistivity and HE XRD. Variations in electrical resistivity (normalized by the electrical resistivity at room temperature) versus temperature are shown in figure 3a. The behaviour is similar to that obtained for other $\beta$-metastable alloys transformed on heating from the $\beta$ metastable state [18][19]. Several changes of slope are observed. A decrease in electrical resistivity $\left(\Delta \rho / \rho_{0}\right)$ is measured at the beginning of the heating, from room temperature to $150^{\circ} \mathrm{C}$, that is usually attributed to vanishing of $\omega_{\text {ath }}$ phase [20][18]. Between $150^{\circ} \mathrm{C}$ and about $320^{\circ} \mathrm{C}$ a change in slope is characterized. Following results of the literature [21][22], it is associated with the formation of $\omega_{\text {iso }}$ phase. Its characterization even by HEXRD is difficult at the lower temperatures. From $335^{\circ} \mathrm{C}$ to $400-450{ }^{\circ} \mathrm{C}$ the electrical resistivity increases with temperature. This domain is associated with the evolution $\omega$ phase, and the formation of other nanosized precipitates that were identified either as a base centred orthorhombic phase (called $\alpha$ "iso) when using HEXRD [23][24][25], or when using TEM, the HCP a phase and more recently an ordered face centred orthorhombic structure called O" [26]. The in-situ HEXRD diagram obtained at $450^{\circ} \mathrm{C}$ reveals the presence of an orthorhombic structure. We considered the more commonly reported structure by using this technique [27][28] i.e. the base centred orthorhombic $\alpha$ " iso, similarly to [29]. The present investigation cannot define if the structure is that of $\alpha$ ", of a distorted $\alpha$, or of O". We call it further $\alpha^{\prime \prime}$ iso $/ \alpha$.

As temperature increases the $\alpha^{\prime \prime}$ iso $/ \alpha$ peaks increase. From $400^{\circ} \mathrm{C}$ to $800^{\circ} \mathrm{C}$, the resistivity decreases. It can be associated with the evolution of the $\alpha^{\prime \prime}$ iso $/ \alpha$ phases, which structure evolves toward the HCP structure of the $\alpha$ phase and which amount should 
decrease. During the slow cooling $\left(0.23^{\circ} \mathrm{C} / \mathrm{s}\right)$, a continuous increase in electrical resistivity is measured that indicates the further increase of $\alpha$ phase amount. A few HEXRD diagrams are shown in Figure $3 \mathrm{~b}$.
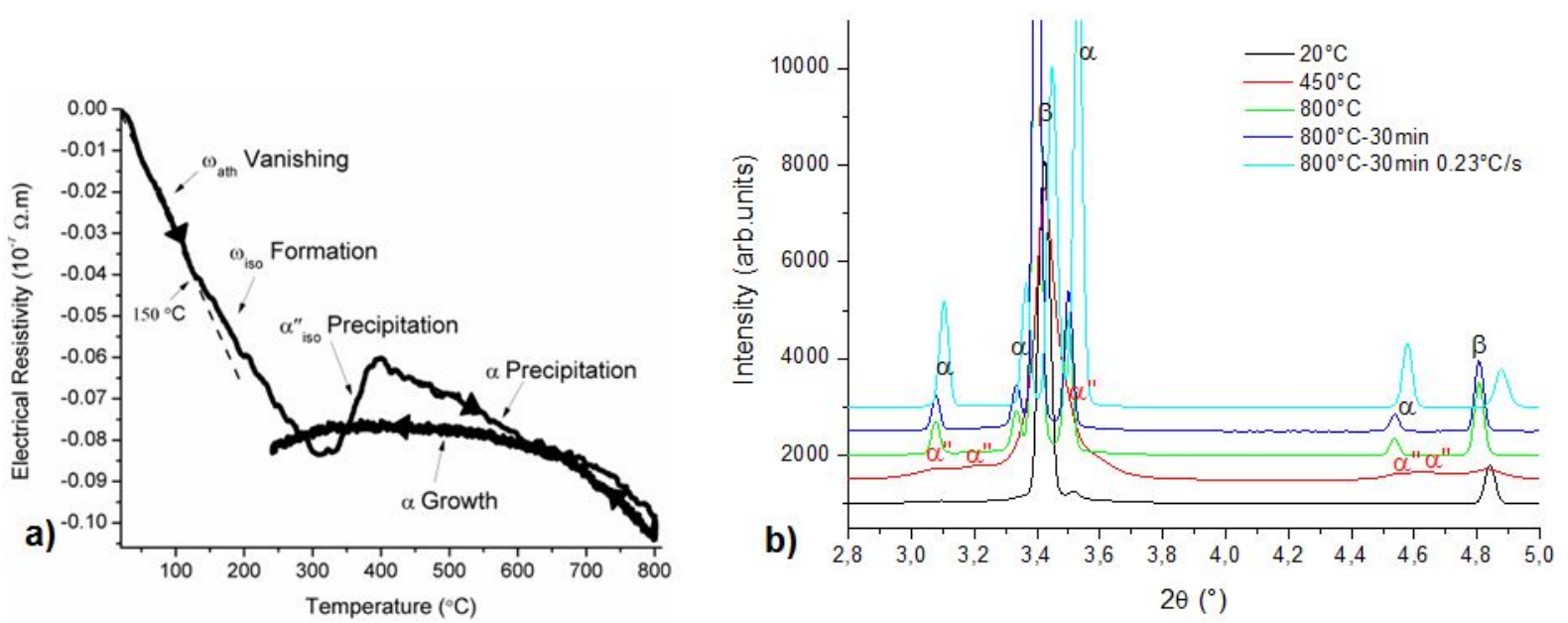

Figure 3: In-situ resistivity variations during SPS thermal process and XRD diffractograms during heating.

SEM micrographs of specimen quenched at the end of holding at $800^{\circ} \mathrm{C}$ and after slow cooling are shown in Fig 4 . For specimen quenched after holding at $800^{\circ} \mathrm{C}, \alpha$ phase is observed at the previous $\beta$ grain boundaries $\left(\alpha_{\mathrm{GB}}\right.$ morphology) with a Precipitate Free Zone (PFZ). Small intragranular $\alpha$ precipitates are uniformly formed in the $\beta$ grains. They exhibit a fine needle shape at the end of holding (Fig. 4a). After slow cooling, the size of $\alpha_{\mathrm{GB}}$ remains nearly the same. However; the intragranular precipitate grew and their morphology is more lamellar (Fig. 4b). The PFZs are less marked.

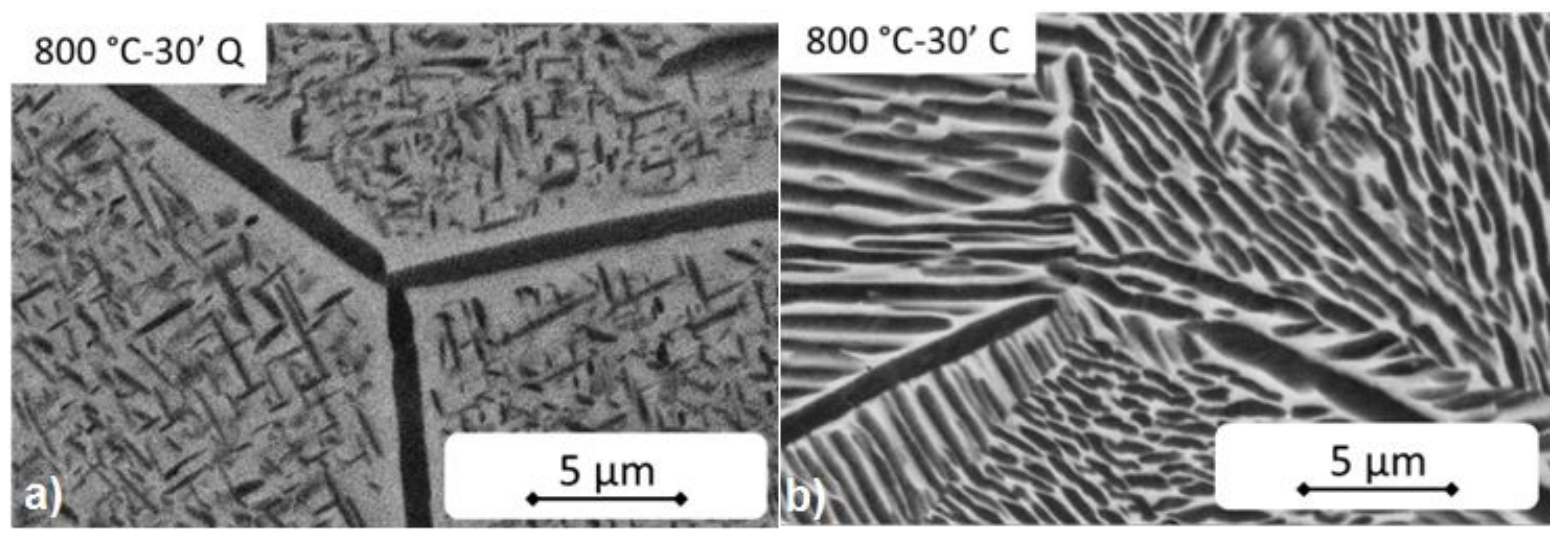

Figure 4: Microstructures of IP $\beta-C e z$ alloy a) after holding at $800^{\circ} \mathrm{C}$ b) after complete SPS thermal path

\subsection{Transformation kinetics in mechanically milled powder}

Transformation kinetics for MM powders were obtained from HEXRD experiment. A few diffractograms are given Fig $5 \mathrm{a}$, and the phase amounts obtained by Rietveld refinement are presented Fig 5b. During the heating of MM powder, the diffraction peaks of $\alpha^{\prime \prime}$ phase are still present. They evolve up to about $590^{\circ} \mathrm{C}$ and tend toward the peak position of the $\alpha$ phase. The $\alpha^{\prime \prime}$ phase amount decreases slowly (about $58 \%$ at $590^{\circ} \mathrm{C}$ ). From $690^{\circ} \mathrm{C}$ to $800{ }^{\circ} \mathrm{C}$, the fraction of $\alpha$ phase sharply decreases $($ as could be expected from thermodynamic data) and it remains nearly constant during the holding. During the cooling, the fraction of $\alpha$ increases while that of $\beta$ decreases. No other phase has evidenced. 

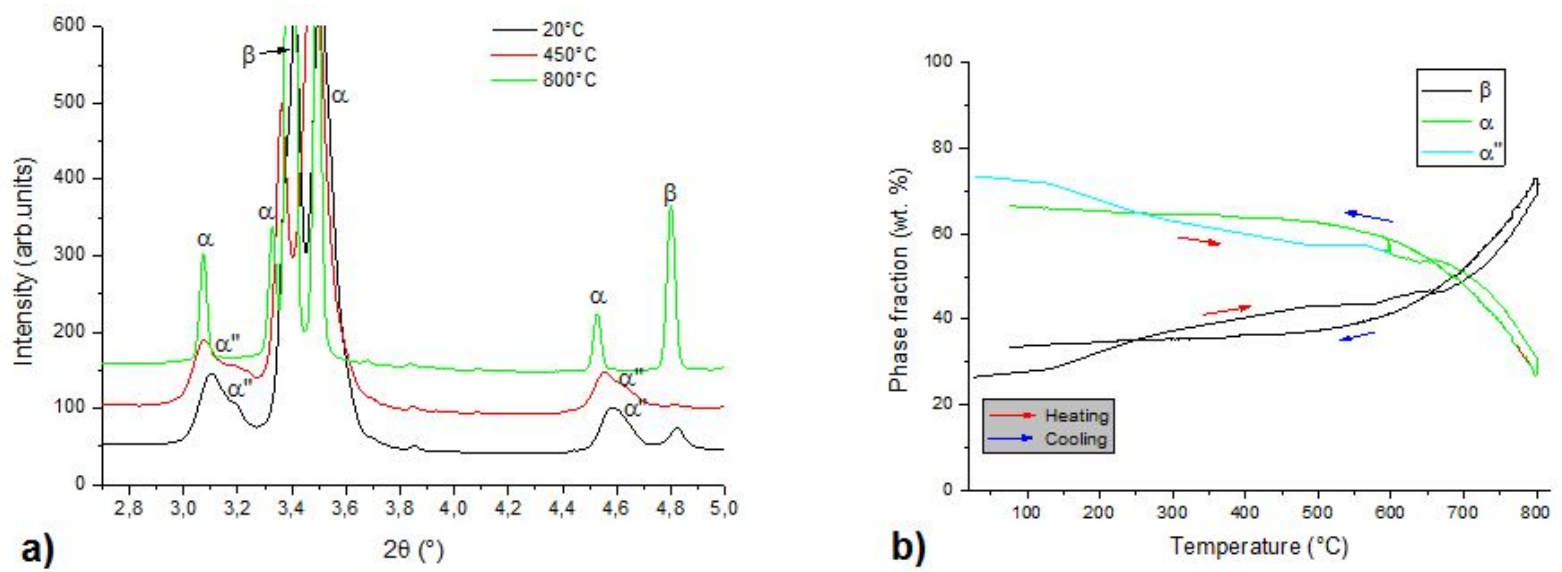

Figure 5: MM-powder during SPS thermal path: a) XRD diffractograms during heating b) Phase fraction evolution during heating.

The microstructures obtained at different steps of the heat treatment are shown in Fig 6. At the end of the heating, the $\alpha$ grains are very thin (Fig 6a). Some differences can be noticed with $\alpha_{W I}$ precipitates having a more lamellar shape in the core and a more nodular one in the shell. After 30 min holding at $800^{\circ} \mathrm{C}$ (Fig 6b), a change in a morphology is observed. BSE micrographs are more contrasted and highlight the nodular morphology in the powder shell and a lamellar morphology in the powder core; a coarsening of the precipitates could occur. The slow cooling leads to the growth of the $\alpha$ precipitates in the shell as well as in the core. For the lamellar precipitates, the growth seems more effective in the width while nodular precipitates seem to grow homothetically (Fig. 6c). The lamellar $\alpha$ precipitates are homogeneously distributed in the $\beta$ grains, with a well-defined orientation that can be considered as inherited from the $\alpha$ " laths orientation.

The microstructures observed in MM powders are very similar to the one observed in the MM-SPS specimen shown Fig 6d. Indeed, compacting the powders leads to a harmonic structure with a shell composed of nodules and a core composed of lamellae (fig. 6d).

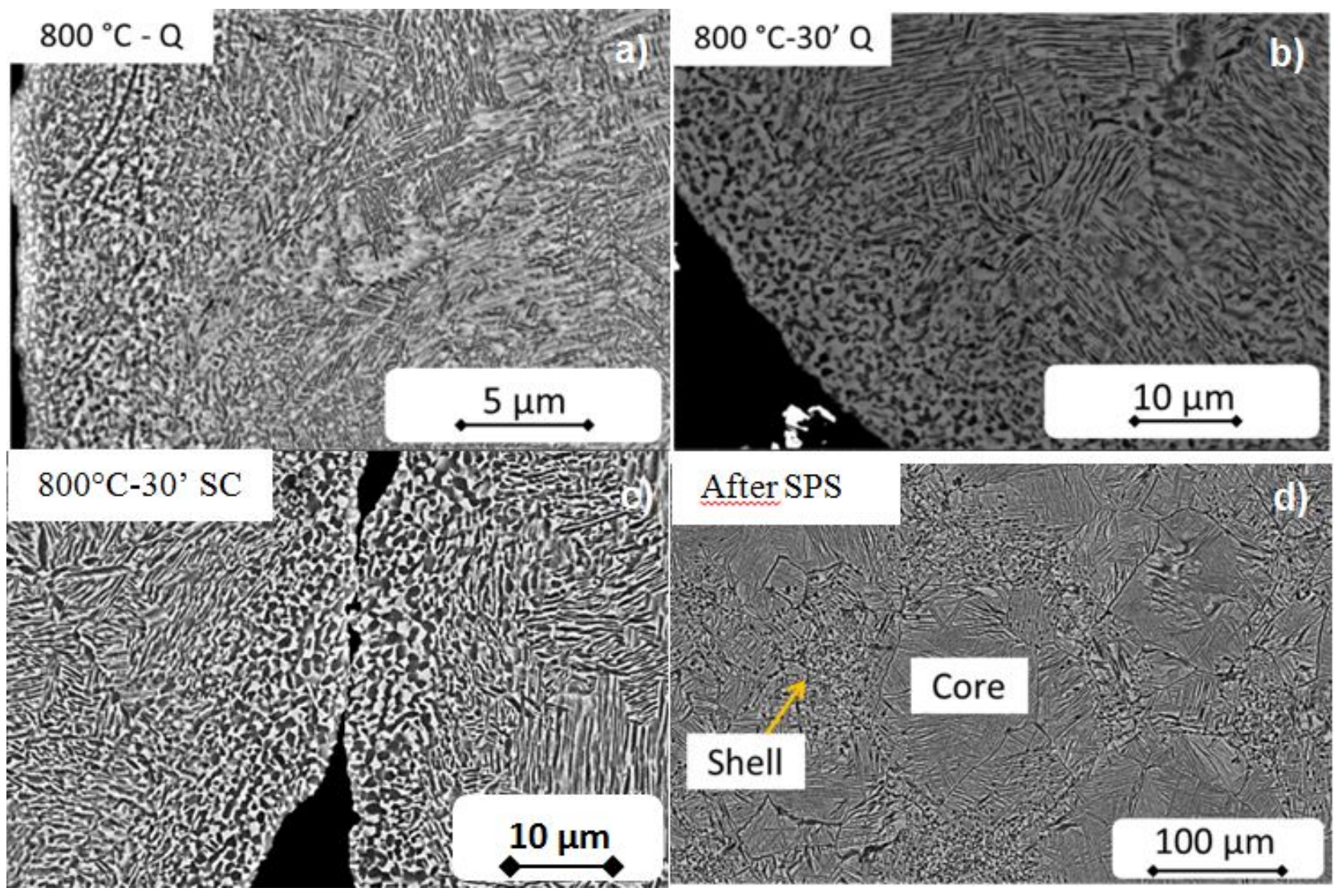

Figure 6: Microstructures of MM powder a) after heating at $800^{\circ} \mathrm{C}$ b) after holding at $800^{\circ} \mathrm{C}$ c) after similar SPS thermal path d) sample using MM powders after SPS process. 
In order to understand the development of $\alpha$ nodules in the deformed area of the powder, IPF maps were characterized in the core and the shell of MM powder thermally treated at $800{ }^{\circ} \mathrm{C}$ for $30 \mathrm{~min}$ followed by helium quenching. In the powder core and in the same $\beta$ grain, the IPF map of $\alpha$ phase, Fig $7 \mathrm{a}$, exhibits clusters of $\alpha$ lamellae with the same variant. The cluster size is about 5 to $10 \mathrm{~mm}$. We can assume that these single $\alpha$ variant clusters are inherited from a group of single variant $\alpha$ " martensite plates as shown in Fig $1 \mathrm{~b}$.

In the powder shell, $\alpha$ and $\beta$ grains are randomly oriented (Fig. 7a and 7b). The $\alpha$ grains are smaller (about $1 \mathrm{~mm}$ ) and nearly nodular. Many fine $\beta$ grains (size of about $1 \mathrm{~mm}$ ) are observed with different orientations.

To confirm this observation, we measured the $\beta / \beta$ grain boundary misorientations in the core and in the shell; the cumulative relative frequency of grain misorientation for each area is shown figure 7c. In the core (subset 1), we can observe that $90 \%$ of the $\beta / \beta$ grain boundaries have a misorientation angle below $5^{\circ}$, so we are well in one $\beta$ grain. In the deformed part (subset 2 ), 20\% of $\beta /$ $\beta$ grain boundary misorientations have a misorientation angle larger than $15^{\circ}$. These results confirm the rotation of the initial larger $\beta$ grain and the development of subgrains, then little $\beta$ grains, during the deformation and heating [30]. Recovery and recrystallization processes must be involved to minimize the elastic and interfacial energies [31]. Concerning the $\alpha$ phase, the globular shape formation may result from a mechanism similar to the formation of nodular $\alpha$ phase at the higher temperatures by forging and further heat treatments. The deformed initial martensite plates are dissolved during the heating favouring grain boundary graving and $\alpha$ nodules formation during forging in the temperature range of $\alpha+\beta$ in order to minimize elastic and interfacial energies.

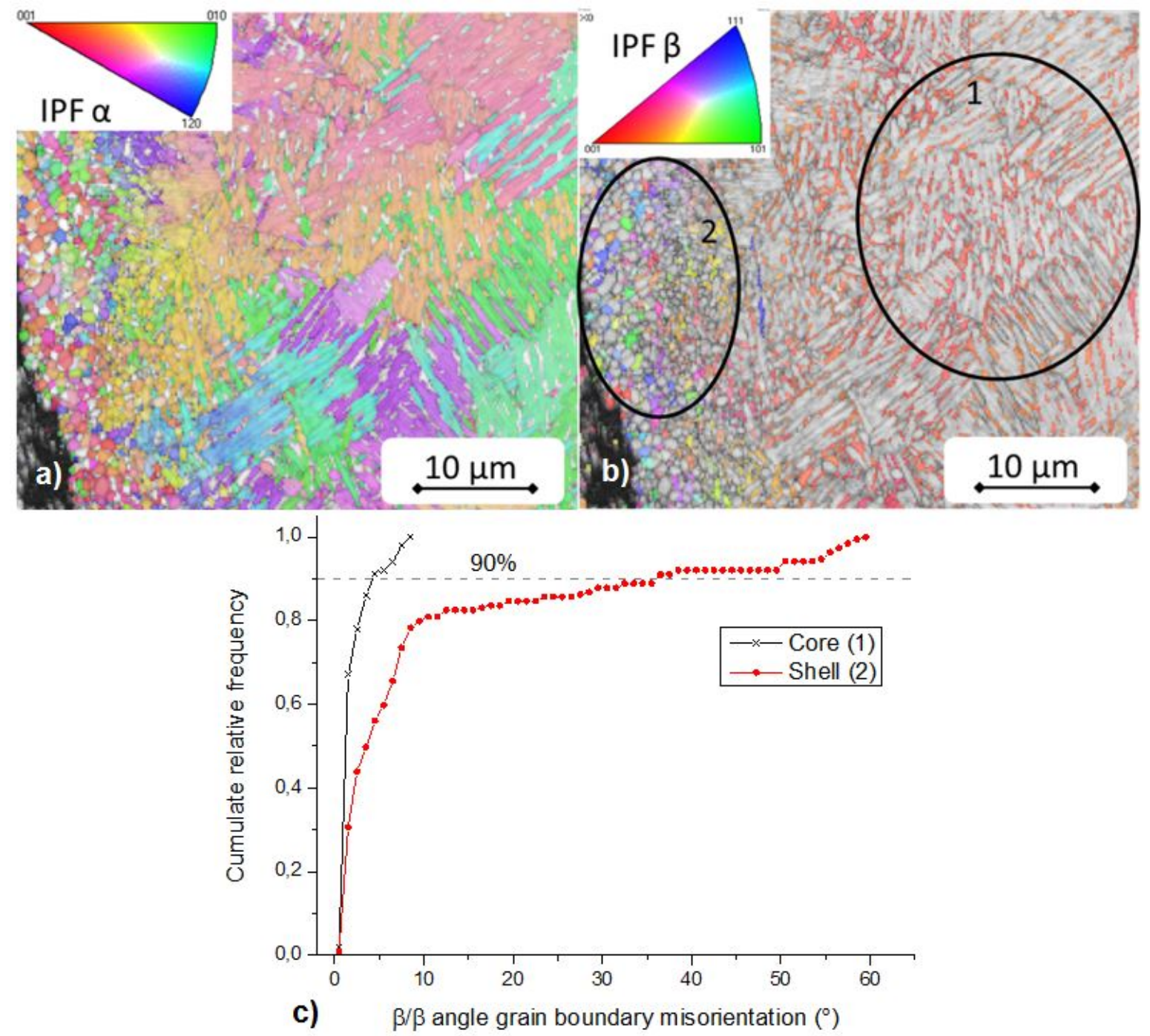

Fig. 7 EBSD IPF $\alpha$ (a) and IPF $\beta$ (b) maps with c) corresponding $\beta / \beta$ misorientation at core and shell areas.

\section{Conclusion}


A harmonic microstructure could be obtained in $\beta$-CEZ alloy after powder mechanical milling and further SPS heat treatment in the $\alpha+\beta$ temperature range. The analysis of structure and microstructure evolutions allowed to explain the different steps in the harmonic structure formation:

- Mechanical milling at room temperature introduces strain-induced martensite in the powder core and shell, as well as very

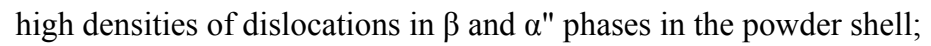

- During the heating, $\alpha^{\prime \prime}$ plates don't dissolve. HEXRD reveals that $\alpha^{\prime \prime} \rightarrow \alpha$. In consequence, each $\alpha$ variant is inherited from

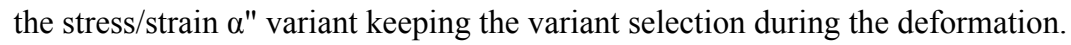

- In the powder shell, the heavy deformation leads to recovery followed by recrystallization for both $\alpha " / \alpha$ and $\beta$ giving small $\alpha$ and $\beta$ grains with size below $1 \mu \mathrm{m}$.

- In the MM powder core, no recovery/recrystallisation occurred; the $\alpha$ lamellae keep a low shape factor (width/length) that is significantly lower than that of $\alpha$ lamellae in IP-specimen.

\section{Acknowledgement}

This work was supported by the French National Research Agency, in the framework of ANR 14-CE07-0003 "HighS-Ti" program and through the program "Investment in the future" referenced by Labex DAMAS. The authors gratefully acknowledge the European Synchrotron Radiation Facility (ESRF) for provision of beam time at beamline ID15A.

\section{References}

1. G. Lütjering, J.C. Williams, Titanium, second ed., Springer, Berlin, 2007.

2. R.R. Boyer, Mat. Sci. and Eng. 213, 1-2 (1996) 103-114.

3. H. Jin, D. J. Lloyd, Scripta Materialia. 50 (2004) 1319-1323.

4. B. Srinivasarao, K. Oh-ishi, T. Ohkubo, T.Mukai, K.Hono, Scripta Materialia. 58, 9 (2008) 759-762.

5. S. K.Vajpai, C. Sawangrat, O. Yamaguchi, O.P. Ciuca, K. Ameyama, Mat. Sci. Eng. C 58 (2016) 1008-1015.

6. Z. Zhang, S.K. Vajpai, D. Orlov, K. Ameyama, Mater Sci Eng A, 598 (2014) 106-113.

7. T. Sekiguchi, K. Ono, H. Fujiwara, K. Ameyama, Mater Trans. 51 (2010) 39-45.

8. T. Sekiguchi, NBR. Sabrina, R. Imao, H. Fujiwara, K. Ameyama, ZH. Zhao, A. Ueno. Proceeding paper - Ti2011.

9. G. Dirras, D. Ueda, A. Hocini, D. Tingaud, K. Ameyama. Scrip. Mat., 138 (2017) 44-47.

10. B. Prandi, E. Alheritiere, F. Schwartz, M. Thomas. Proceedings paper -Ti1988, Ed. de Physique, Ed. P. LACOMBE, R. TRICOT et G. BERANGER, 811-818.

11. M. Tokizane, T. Fukam, T. Inaba. ISIJ International, 31 (1991) No. 10, 1088-1092.

12. B. Denand, M. Dehmas, E. Aeby-Gautier, C. Bonnet, G. Geandier, J-P. Sarteaux. International patent deposed with reference number: PCT/EP2018/07178.

13. J. Kieffer, D. Karkoulis. PyFAI, Journal of Physics: Conference Series, IOP Publishing 425 (2013) 202012.

14. H.M. Rietveld : J. Appl. Cryst. 2 (1969) 65-71.

15. G. Geandier, E. Aeby-Gautier, A. Settefrati, M. Dehmas, B. Appolaire. C. R. Physique 13 (2012) 257-267.

16. TW Duerig, JC Williams. Proceedings of the Symposium. Atlanta, GA (1984) 19-67.

17. T. Grosdidier, M.J. Philippe. Materials Science and Engineering A291 (2000) 218-223.

18. J.C. Ho and E. W. Collings. Phys. Rev. B 6 (1972) 3727-3738.

19. R. Sanguinetti, M. Zandona, A. Pianelli, E. Aeby-Gautier. Journal de Physique IV, Vol. 4 (1994) 99-104.

20. P. Zhanal, P. Harcuba, J. Smilauerova, J. Strsky, M. Janecek, B. Smola, M. Hajek. Acta. Phys. Pol. A, 128 (2015) $779-782$.

21. S. Nag, R. Banerjee, R. Srinivasan, J.Y. Hwang, M. Harper, H.L. Fraser. Acta Materialia 57 (2009) $2136-2147$.

22. T. Li, D. Kent, G. Sha, L. T. Stephenson, A. V. Ceguerra, S. P. Ringer, M. S. Dargush, J. M. Carnei Acta Materialia 106 (2016) 353-366.

23. E. Aeby-Gautier, A. Settefrati, F. Bruneseaux, B. Appolaire, B. Denand, M. Dehmas, G. Geandier, P. Boulet. Journal of Alloys and Compounds, 577S (2013) S439-S443.

24. A.R.G. Brown, D. Clark, J. Eastabrook, K.S. Jepson, Nature 201 (4922) (1964) 914-915. 
25. M.H. Mueller, R.L. Hitterman, H.W. Knott, Acta Crystallogr. 15 (1962) 421.

26. Y. Zheng, R.E.A. Williams, H.L. Fraser, Scripta Mater. 113 (2016) 202-205.

27. P. Barriobero-Vila, G. Requena, S. Schwarz, F. Warchomicka, T. Buslaps, Acta Mater. 95 (2015) 90-101.

28. H. Chang, E.A. Gautier, L. Zhou, Chin. Sci. Bull. 59 (15) (2014) 1773-1777.

29. N. Maury, B. Denand, M. Dehmas, C. Archambeau-Mirguet, J. Delfosse, E. Aeby-Gautier Journal of Alloys and Compounds 763 (2018) 446-458

30. D. Qin, D. Guo, L. Zheng, Y. Li. Journal of alloys and compounds, 769 (2018) 725-731.

31. A Settefrati, B. Appolaire, E. Aeby-Gautier, Y. Le Bouar, G. Khelifati. Proceeding paper - Ti2011. 